\title{
Mapping Bedrock Beneath Glacial Till using CDP Seismic Reflection Methods
}

\author{
Dean Keiswetter, Ross Black and Don Steeples \\ Department of Geology, University of Kansas Lawrence, Kansas
}

\begin{abstract}
This paper is a case history demonstrating the applicability of the common depth point (CDP) seismic reflection method to image bedrock beneath glacial till in northwestern Iowa. Reflections from the base of the $40-\mathrm{m}$ thick glacial till are clearly observable on field files at around 45 to $50 \mathrm{~ms}$ two-way traveltime and possess a dominant frequency of around $100 \mathrm{~Hz}$. The bedrock reflection is confirmed by drill data. The seismic data are of sufficient quality to detect local bedrock topographic changes and to interpret discontinuities along the till-bedrock interface. Finite-difference synthetic seismograms substantiate the interpreted reflections and the diffraction signatures from faults observed on the field files. At some locations along the seismic line, intra-till reflections are apparent on the field files. These intra-till features are on the order of tens of meters in length along the line traverse and reflections from them are not enhanced by common depth point processing. Intra-till reflections could be indicative of gravels or other alluvial materials that may serve as local aquifers.
\end{abstract}

\section{Introduction}

Detailed knowledge of the bedrock topography beneath glacial till is often important to locate and identify productive groundwater reservoirs and to map potential hydrologic barriers. In addition, intra-till reflectors can be important as aquifers or as preferential flow paths for contaminants at polluted sites. Various geophysical methods have been successfully employed to image the base of glacial tills, including resistivity (Lennox and Carlson, 1967), gravity (Carmichael and Henry, 1977), seismic refraction (Haeni, 1986) and seismic reflection (Warrick and Winslow, 1960; Hunter et al., 1984) surveys. The CDP method has not, however, been widely utilized to image bedrock beneath glacial till. This paper demonstrates the feasibility of using the CDP method to image bedrock topography beneath glacial till and of using individual field files to detect intra-till reflectors at depths less than $40 \mathrm{~m}$ in north central Iowa.

The identification of reflections on unprocessed field files is critical to a confident interpretation of CDP processed highresolution seismic data. As the two-way travel time decreases, reflection recognition is complicated by increased interference from non-reflection events, and by changes in reflection character with increasing shot-to-receiver offset (Hunter et al., 1984; Pullan and Hunter, 1985). Positive identification of reflections is necessary in order to separate and reduce refraction energy (commonly the earliest seismic energy) without degrading early reflections (Steeples and Miller, 1990). If not properly handled before stacking, refractions can be mis-interpreted as reflections and can create artificial structures. Results from modeling can be

Copyright 1994 by the American Geophysical Union.

Paper number 94GL00051

0094-8534/94/94GL-00051\$03.00 used to differentiate reflections and to aid design of processing parameters.

The seismic data presented in this paper are a subset of a 17$\mathrm{km}$ long, high-resolution seismic line acquired within the Manson Impact Structure (MIS), Iowa (Figure 1). The MIS, at approximately $35-\mathrm{km}$ in diameter, is the largest known bolide impact feature in North America, but the structure is completely obscured by a thick glacial till cover.

\section{Quaternary Geology}

Bedrock lithologies consist of lower Cretaceous shales and sands northwest of the MIS and Pennsylvanian shale, sandstone and limestone to the southeast (Munter et al., 1983). Most of northwest/central Iowa, and all of the study area, is overlain by 30 to $90 \mathrm{~m}$ of Quaternary glacial till. Repeated glacial advances during Pleistocene time deposited several till layers along with occasional intra-till alluvial layers. The surficial glacial till is classified rock-stratigraphically as the Dows Formation (Kemmis et al., 1981). The Dows Formation till, deposited approximately 12,000 to 14,000 years before present, forms the prominent physiographic region known as the Des Moines Lobe and represents the southwestern-most extension of the Late Wisconsinan Laurentide ice sheet (Munter et al., 1983; Ruhe, 1969). The Dows Formation is characterized by poorly developed drainage networks, knob and kettle topography, and a variety of morainal features. The thickness and composition of till deposits are highly variable due in part to local preQuaternary topography (possibly controlled by impact-induced faults), multiple periods of erosion and deposition, and postglacial processes.

\section{Significance of Mapping the Bedrock Interface}

The ability to determine till thickness in this region is important for a variety of reasons related to the water-supply. First, surface-water reservoirs are widely spaced and uncommon. River valleys and associated alluvial aquifers are locally deeply incised but this dissection extends only a short way back from the valleys, commonly less than $1.5 \mathrm{~km}$ (Kemmis et al., 1981). As a result, the interfluve areas are quite broad and the majority of water must be obtained from wells. Second, although lenticular sand and gravel units within or between the tills may provide locally abundant water supplies, the tills themselves are not generally conducive to water flow. Therefore, many water wells penetrate sub-till aquifers to sustain a reliable water supply (Munter et al., 1983).

\section{Acquisition/Data Processing}

Data were acquired using a 15-bit, 48-channel engineering seismograph. A downhole 50-cal. rifle was chosen as the optimum source for this survey based on its broad-band source 


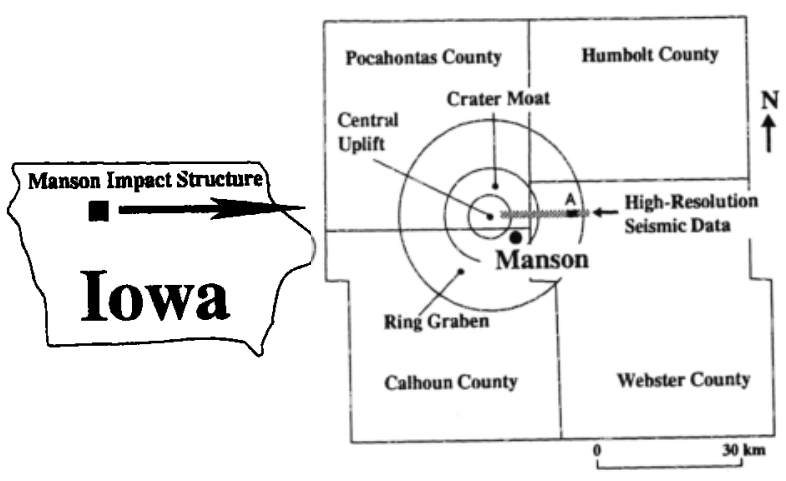

Figure 1. Location map of the Manson Impact Structure. The general location of seismic data shown in figures 2-7 is indicated by the blackened rectangle $A$.

pulse, low ratio of ground-roll to body waves, and total energy output (Steeples et al., 1987). Chosen acquisition parameters included an end-on spread, $10 \mathrm{~m}$ source-, and $5 \mathrm{~m}$ geophone group-spacings, and a $20 \mathrm{~m}$ source-to-nearest receiver offset. Geophone arrays consisted of three $40 \mathrm{~Hz}$ receivers wired in series, evenly distributed over a $1 \mathrm{~m}$ interval, and centered on the stations. Routine quality control practices during acquisition involved a visual analysis of signal-to-noise ratio, environmental noise, DC bias, and the optimum recording window (Hunter et al., 1984) on at least every fifth field plot. The profile line was surveyed for elevation and location accuracy.

Acquisition parameters were chosen after analysis of walkaway noise tests to image features below $100 \mathrm{~m}$. The reason for targeting this depth was to delineate the stratigraphy and small-scale structural configuration of the MIS. Although the survey was designed to target features well below the glacial till, reflections from the base of the glacial till can be seen at $39 \mathrm{~ms}$ on the near traces (Figure 2). The source-to-receiver offsets used represent a compromise between maximizing the range of offsets to improve velocity analysis and maximizing spatial-sampling of shallow reflections to improve reflector coherency.

The seismic data were processed into CDP format at The University of Kansas using software from Somanas et al., (1987) on a 486-based microcomputer. The processing flow was similar to conventional exploration seismic processing flows, but it was

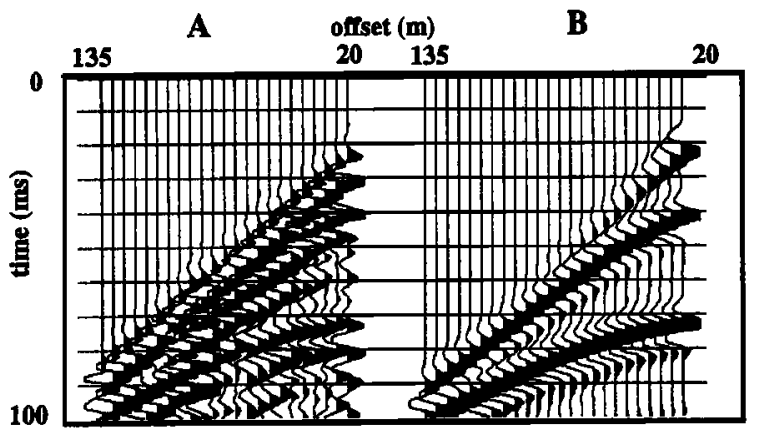

Figure 2. A). Two easily identifiable reflections at $39 \mathrm{~ms}$ and $70 \mathrm{~ms}$ are observed on this unprocessed field file. The $39 \mathrm{~ms}$ event represents the base of the glacial till, and the $70 \mathrm{~ms}$ event is an unidentified, faulted reflector present on Figure 3 between CDP's 830 and 850 . B). Synthetic seismogram, generated by finite difference modeling for a flat-lying three-layer case (layer depths of $37 \mathrm{~m}$ and $70 \mathrm{~m}$ ) corroborates the seismic signatures. Trace spacing is $5 \mathrm{~m}$. optimized for high-resolution data. Specifically, detailed muting procedures and optimal use of static corrections were emphasized during processing of these data. An analysis of refraction statics provided information about local velocity variations that were used during normal-moveout procedures (Disher and Naquin, 1970). Surface-consistent static operations were limited to $3 \mathrm{~ms}$ (less than 1/4 wavelength) and applied before stacking the data. Non-surface consistent static corrections were limited to a maximum of $2 \mathrm{~ms}$ shift and applied after stacking. The use of non-surface consistent static corrections improved the appearance of the final section without changing the interpretation.

Stacking velocities were derived from CDP gathers without dip-moveout correction. The velocities chosen were those which produced the most coherent and highest-frequency reflection events. The lack of dip compensation may slightly distort the frequency content and spatial location of reflection wavelets on a stacked section.

\section{High-Resolution Seismic Data}

A reflection from the till-bedrock interface dominates the CDP-stacked section and is observed on individual field files (Figures 2-4). The hyperbolic move-out and consistent wavelet characteristics of the bedrock reflection allow a confident identification. The dominant frequency of the reflection data is in excess of $100 \mathrm{~Hz}$. Small scale structural blocks bounded by faults characterize the sub-till geology.

Depth to bedrock varies approximately $13 \mathrm{~m}$ between the local high at CDP 1050 and the low at CDP 730, a distance of $800 \mathrm{~m}$. Indications of faulting on the unmigrated CDP section include two-way traveltime shifts (CDP 825, Figure 3) and diffraction patterns (CDP's 935 and 1040, Figures 3 and 4). The interpreted faults shown in figures 3 and 4 are based upon the signal character of the CDP stacked data, field files, and synthetic seismograms (Figures 3-6). Using multiple techniques to identify fault signatures is important because interpretations based solely upon CDP-processed data may be unreliable due to potential

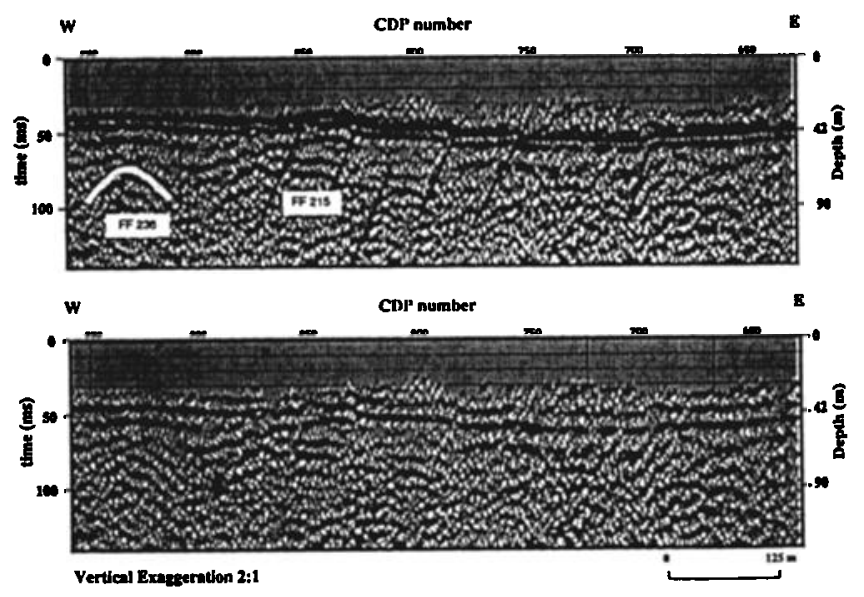

Figure 3. A reflection from the base of the glacial till dominates this 6-fold CDP stacked section; top-interpreted, bottom-uninterpreted. The dark stippling represents the glacial till-bedrock interface, and lighter stippling highlights diffractions. Unidentified laterally-discontinuous reflections and abundant diffraction patterns are observed beneath the bedrock reflector indicating complex structure. A depth scale shown on the right is approximate due to lateral velocity variations present along the line. The field file numbers (FF \#) on the stacked section correspond to files shown in Figure 5. 

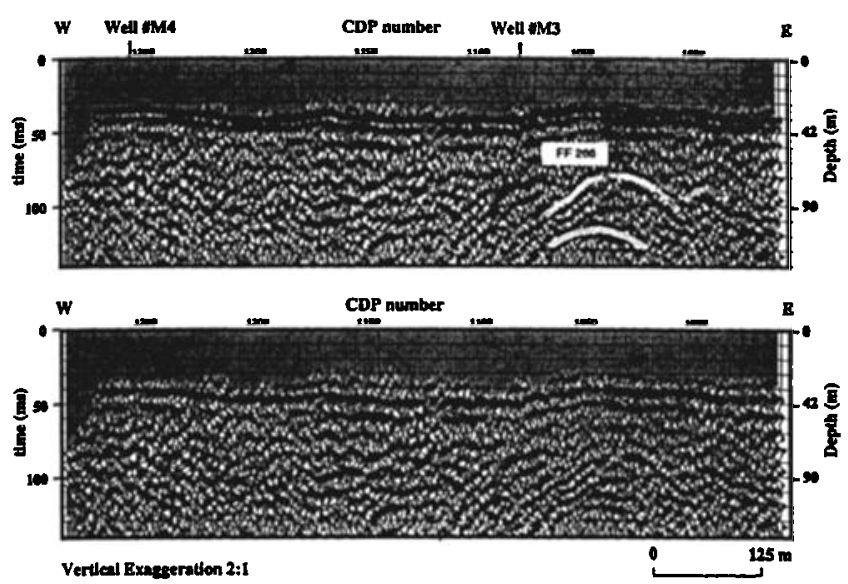

Figure 4. Westward continuation of the seismic line shown in figure 3. See Figure 3 for details.

processing artifacts. Synthetic seismograms illustrate various seismic responses to faulting. The synthetics support our interpretation of the reflection from the base of the till and also corroborate our interpretation of the fault signatures (Figures 2, 6).

Two research wells located along the line, the M-4 and M-3 wells located at CDP numbers 1256 and 1080 respectively (Figure 4), constrain the seismic data and allow for confident bedrock identification. Logs from both wells report the base of till at a depth of $40 \mathrm{~m}$. Bedrock lithologies consist primarily of silty, calcareous gray shale with abundant ironstone concretions and shell debris (Anderson et al., 1993).

Laterally discontinuous reflections from depths shallower than bedrock are observed on some of the field files. Identification of the intra-till reflectors is based on a detailed analysis of the moveout along potential reflection hyperbolae (Figure 7). On the file shown in figure 7, a least-squares-fit of the reflection event at $40 \mathrm{~ms}$ two-way traveltime provides an NMO velocity of about $1700 \mathrm{~m} / \mathrm{s}$ and a depth of approximately $31 \mathrm{~m}$. A second reflector, observed at $51 \mathrm{~ms}$ on the near source-to-receiver traces, has an NMO velocity of around $1800 \mathrm{~m} / \mathrm{s}$ and a calculated depth of 42 $\mathrm{m}$. The latter reflection corresponds within two meters in depth to the till/bedrock interface as reported by drill data. Because the two reflections have distinct frequency characteristics and NMO

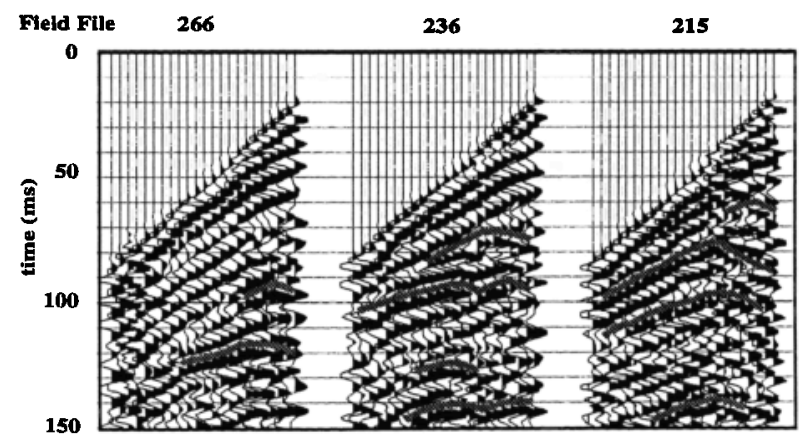

Figure 5. Potential fault signatures observed on selected field files indicate complex structures and are highlighted with stippling. Identification of faults and/or diffractions on field files strengthens interpretation of the CDP-stacked data. The sourceto-nearest-receiver offset is $20 \mathrm{~m}$, and trace spacing is $5 \mathrm{~m}$.

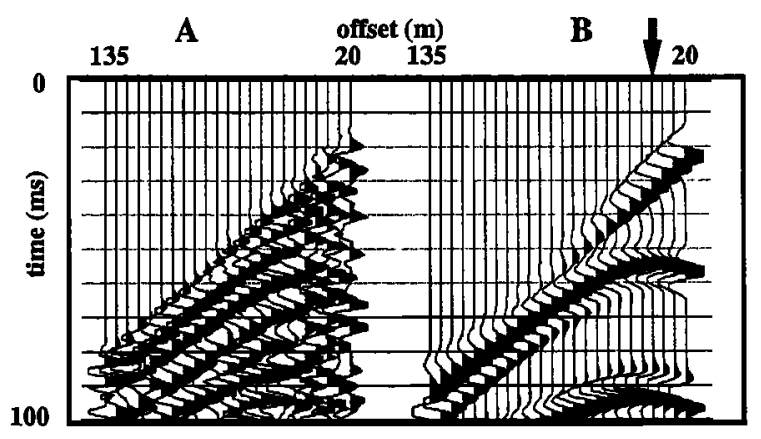

Figure 6. Comparison of fault signatures observed in raw data (A) and a synthetic seismogram (B). The event around $90 \mathrm{~ms}$ on the synthetic $(B)$ is a surface multiple, indicating the latter events on (A) may be multiples as well. A step fault located beneath the arrow was used as the geologic model for the synthetic seismogram. Trace spacing for both seismograms is $5 \mathrm{~m}$.

velocities, they are interpreted to represent different units. The lower frequency content of the $40 \mathrm{~ms}$ reflector may indicate a gradational acoustic contrast between the till and the intra-till reflector than at the till/bedrock interface.

\section{Discussion}

A reflection from the base of the glacial till is identifiable on field files, supported by synthetic seismograms, confirmed by drilling, and is traceable over long distances. In addition to depth-to-bedrock variations, diffractions which identify faults or wavelength-scale erosional features are clearly seen in the data. Fault signatures in the bedrock reflection may indicate fault reactivation during glaciation. Conversely, if the faults were not reactivated during the Pleistocene, they may indicate lateral velocity or density changes in the bedrock, presumably caused by the meteorite-induced faults and resulting preferential erosion of the pre-glacial topography. On the basis of the high-resolution data, the structural blocks that underlie the glacial till within the ring graben of the MIS are on the order of tens of meters across. This interpretation is consistent with drill information and impact morphology (Anderson et al., 1993; Melosh, 1989).

Examination of individual field files reveals numerous shallow reflections, indicating complex near-surface stratigraphy (Figure

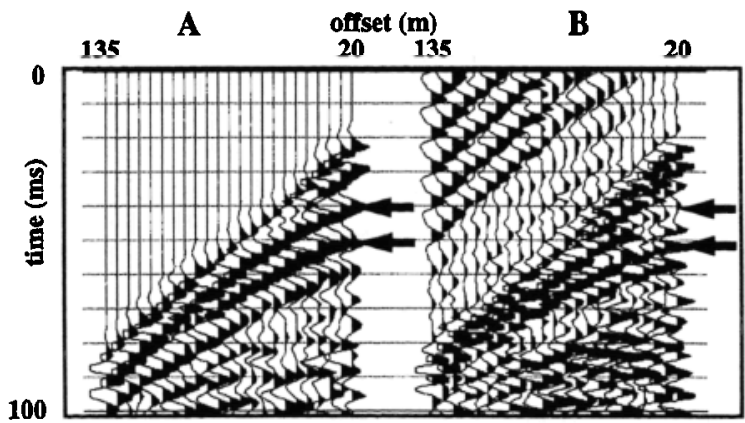

Figure 7. Analysis of reflection events on field files reveals complex near-surface stratigraphy; (A) unprocessed field file, and (B) same file after application of a tapered bandpass filter passing $200-$ to $350-\mathrm{Hz}$ information. Reflections marked by the arrow are interpreted to represent different units due to their distinct frequency characteristics and NMO velocities. The event at 50 ms corresponds to the base of the till at about $40 \mathrm{~m}$ depth, while the reflection at around $40 \mathrm{~ms}$ corresponds to an unknown intratill reflector at a depth of around $31 \mathrm{~m}$. The trace spacing is $5 \mathrm{~m}$. 
7). Many of the shallow reflections, ranging in two-way traveltime between 30 and $40 \mathrm{~ms}$, are observed on only a few consecutive files, indicating lateral dimensions of tens of meters along the line. Analysis of individual field files may provide more geologic information than CDP-processed seismic data when the geologic targets change rapidly along the line. We cannot determine the nature of the intra-till reflectors because the drill data, which were acquired prior to the seismic data and targeted strata beneath the glacial till, did not record intra-till lithologies.

CDP processing of the seismic data tends to obscure the intratill reflectors because of their limited horizontal extent, the inherent smearing effect of CDP processing, and the acquisition parameters used. If intra-till reflections are caused by either paleodrainage or buried glacial features such as eskers within older tills, they would be expected to have lateral extents of the order of tens of meters. Because that is the scale of the horizontal extent of the intra-till reflections, we believe that they are showing us the locations of such intra-till features that may be of hydrologic interest. Using different field parameters, it would be possible to design a seismic survey targeting depth ranges of less than $60 \mathrm{~m}$ to better image the laterally limited shallow reflections.

There is an approximate $10 \%$ uncertainty in the calculated stacking velocities. This uncertainty is due to the limited range of offsets that image shallow reflectors in our data, the unavoidable static shifts associated with seismic data acquired on land, and the slight perturbations in the non-hyperbolic moveout associated with inhomogeneous media. These velocity inaccuracies result in depth errors of 3 to $4 \mathrm{~m}$ for reflector depths of $40 \mathrm{~m}$. A depth uncertainty of this magnitude does not significantly affect our interpretations.

\section{Conclusion}

The CDP seismic-reflection method has been shown to be useful for mapping bedrock beneath glacial till in north central Iowa. This information can be used to identify shallowsubsurface faults, to direct water-well placement, to locate potential hydrogeological barriers and preferential contaminant flow paths, or to enhance datum corrections during seismic processing of deeper reflections. Intra-till reflectors were observed in the field files but could not be enhanced during CDP processing due to their limited horizontal extent, the inherent smearing effect of CDP processing, and the acquisition geometries used. While the data shown here were part of a survey with objectives a few hundred meters deep, they suggest that seismic reflection surveys designed to image the base of the glacial till could accurately image bedrock topography and intratill reflectors at local to regional scales.

Acknowledgments. This research was funded by the National Science Foundation Contract \# EAR-9211602. We thank Ray Anderson from the lowa Department of Natural Resources for providing borehole information, Rick Miller and seismic crew members from the Kansas Geological Survey for working with us to acquire these seismic data, and two anonymous reviewers for their helpful and constructive comments.

\section{References}

Anderson, R. R., Witzke, B. J., Hartung, J. B., Shoemaker, E. M., and Roddy, D. J., Descriptions and preliminary interpretations of cores recovered from the Manson Impact Structure Iowa, Lunar and Planetary Science Conf. XXIV, 35-36, 1993.

Carmichael, R. W., and Henry, G., Gravity exploration for groundwater and bedrock topography in glaciated areas, Geophys., 42, 850-859, 1977.

Disher, D. A., and Naquin, P. J., Statistical automatic statics analysis, Geophys., 35, 574-585, 1970.

Haeni, F. P., Application of seismic refraction methods in groundwater modeling studies in New England, Geophys., 51, 236-249, 1986.

Hunter, J. A., Pullan, S. E., Burns, R. A., Gagne, R. M., and Good, R. L., Shallow seismic reflection mapping of the overburdenbedrock interface with the engineering seismograph-some simple techniques, Geophys., 49, 1381-1385, 1984.

Kemmis, T. J., Hallberg, G. R., and Lutenegger, A. J., Depositional environments of glacial sediments and landforms on the Des Moines Lobe, Iowa, Iowa Geol. Survey Guidebook 6, 132 pp., Iowa Dept. Nat. Res., Iowa City, IA., 1981.

Lennox, D. H., and Carlson, V., Geophysical exploration for buried valleys in an area north of Two Hills, Alberta, Geophys., 32, 331$362,1967$.

Melosh, H. J., Impact Cratering, a Geologic Process, 245 pp., Oxford Univ. Press, 1989.

Munter, J. A., Ludvigson, G. A., and Bunker, B. J., Hydrogeology and stratigraphy of the Dakota Formation in northwest Iowa, Iowa Geol. Survey Water Supply Bulletin 13, 55 pp., Iowa Dept. Nat. Res., Iowa City, IA., 1983.

Pullan, S. E., and Hunter, J. A., Seismic model studies of the overburden-bedrock reflection, Geophys., 50, 1684-1688, 1985.

Ruhe, R. V., Quaternary landscapes in Iowa, Iowa State Univ. Press, 255 pp., 1969.

Somanas, C. D., Bennett, B. C., and Chung, Y. J., In-field seismic CDP processing with a microcomputer, The Leading Edge, 24-26, 1987.

Steeples, D. W., and Miller, R. D., Seismic-reflection methods applied to engineering, environmental, and ground-water problems, in Geotechnical and Environmental Geophysics, edited by Stan Ward, pp. 1-30, Soc. Explor. Geophys., 1990.

Steeples, D. W., Miller, R. D., and Knapp, R. W., Downhole .50caliber rifle--an advance in high-resolution seismic sources, (abstract), Soc. Explor. Geophys. 57th Ann. Mtg., 76-78, 1987.

Warrick, R. E., and Winslow, J. D., Application of seismic methods to a ground-water problem in northeastern Ohio, Geophys., 25, 505-519, 1960.

Dean Keiswetter, Ross Black, and Don Steeples, Department of Geology, University of Kansas, Lawrence, KS 66045

(Received December 7, 1993; Accepted January 7, 1994) 